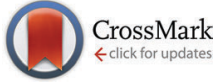

Cite this: Phys. Chem. Chem. Phys., 2016, 18, 2192

Received 6th November 2015 Accepted 1st December 2015

DOI: $10.1039 / c 5 c p 06798 g$

www.rsc.org/pccp

\title{
Connecting defects and amorphization in UiO-66 and MIL-140 metal-organic frameworks: a combined experimental and computational study $\dagger$
}

\author{
Thomas D. Bennett, ${ }^{a}{ }^{a}$ Tanya K. Todorova, ${ }^{b}$ Emma F. Baxter, ${ }^{a}$ David G. Reid, ${ }^{c}$ \\ Christel Gervais, ${ }^{d}$ Bart Bueken, ${ }^{e}$ B. Van de Voorde, ${ }^{e}$ Dirk De Vos, ${ }^{e}$ David A. Keen ${ }^{f}$ \\ and Caroline Mellot-Draznieks*b
}

\begin{abstract}
The mechanism and products of the structural collapse of the metal-organic frameworks (MOFs) UiO-66, MIL-140B and MIL-140C upon ball-milling are investigated through solid state ${ }^{13} \mathrm{C}$ NMR and pair distribution function (PDF) studies, finding amorphization to proceed by the breaking of a fraction of metal-ligand bonding in each case. The amorphous products contain inorganic-organic bonding motifs reminiscent of the crystalline phases. Whilst the inorganic $\mathrm{Zr}_{6} \mathrm{O}_{4}(\mathrm{OH})_{4}$ clusters of UiO-66 remain intact upon structural collapse, the ZrO backbone of the MIL-140 frameworks undergoes substantial distortion. Density functional theory calculations have been performed to investigate defective models of MIL-140B and show, through comparison of calculated and experimental ${ }^{13} \mathrm{C}$ NMR spectra, that amorphization and defects in the materials are linked.
\end{abstract}

\section{Introduction}

Crystalline metal-organic frameworks (MOFs) continue to be of interest to the scientific community due to their high surface areas and related potential for gas sorption, separations, drug delivery and catalysis. ${ }^{1,2}$ Comparatively little attention is however focused on their amorphous counterparts, i.e. those which do not exhibit long range crystallographic order, yet still consist of threedimensional arrays of connected inorganic nodes and organic ligands. ${ }^{3-5}$ The use of pressure, temperature or shear stress to induce transitions between crystalline and amorphous states is of particular intrigue,$^{6-8}$ due to possible uses in reversible sorption, conductive and multiferroic applications. ${ }^{9}$ Whilst computational or experimental characterization of purely inorganic ${ }^{10}$ or organic ${ }^{11}$

\footnotetext{
${ }^{a}$ Department of Materials Science and Metallurgy, University of Cambridge, Cambridge CB3 OFS, UK. E-mail: tdb35@cam.ac.uk

${ }^{b}$ Laboratoire de Chimie des Processus Biologiques, UMR 8229 CNRS, UPMC Univ Paris 06, Collège de France, 11 Place Marcelin Berthelot, 11 Marcelin Berthelot, 75231 Paris Cedex 05, France. E-mail: caroline.mellot-draznieks@college-de-france.fr ${ }^{c}$ Department of Chemistry, University of Cambridge, Lensfield Road, Cambridge, CB2 1EW, UK

${ }^{d}$ Sorbonne Universités, UPMC Univ Paris 06, CNRS, Collège de France, UMR 7574, Chimie de la Matière Condensée de Paris, Paris, France

${ }^{e}$ Centre for Surface Chemistry and Catalysis, Leuven Chem\&Tech, KULeuven, Celestijnenlaan 200F, P. O. Box 2461, 3001 Heverlee, Belgium

${ }^{f}$ ISIS Facility, Rutherford Appleton Laboratory, Harwell Oxford, Didcot, Oxfordshire OX11 OQX, UK

$\dagger$ Electronic supplementary information (ESI) available: ${ }^{13} \mathrm{C}$ NMR, DFT, PDF analysis. See DOI: $10.1039 / \mathrm{c} 5 \mathrm{cp} 06798 \mathrm{~g}$
}

amorphous frameworks is known, structural insight into amorphous MOFs (aMOFs) is largely limited to those which adopt similar network topologies to the zeolite family. ${ }^{12}$

Mechanochemistry, or ball-milling is increasingly utilized to synthesize crystalline MOFs in relatively large quantities with minimal solvent use. ${ }^{13}$ Curiously, and unlike inorganic porous materials, MOFs are highly susceptible to collapse using the same treatment. ${ }^{14}$ Whilst this can be mitigated by pore-filling prior to treatment, it remains problematic given the use of ballmilling as a common post-processing method to increase external surface area. ${ }^{15,16}$ This propensity for collapse has previously been linked to the low shear moduli of the family, ${ }^{17}$ although recent reports have emerged that appear to contradict this argument. ${ }^{18,19}$

The zirconium-based MOF UiO-66 $\left[\mathrm{Zr}_{6} \mathrm{O}_{4}(\mathrm{OH})_{4}\left(\mathrm{O}_{2} \mathrm{C}^{-} \mathrm{C}_{6} \mathrm{H}_{4}{ }^{-}\right.\right.$ $\left.\left.\mathrm{CO}_{2}\right)_{6}\right]^{20}$ crystallizes in the space group $\mathrm{Fm} \overline{3} \mathrm{~m}$, and consists of $\mathrm{Zr}_{6} \mathrm{O}_{4}(\mathrm{OH})_{4}$ octahedra connected together by benzene-1,4dicarboxylate (bdc) linkers in three dimensions. ${ }^{21}$ The inorganic cluster has a twelve-fold coordination and each $\mathrm{Zr}^{4+}$ ion is connected to four intra-cluster oxygen atoms, and four distinct carboxylate linkers (Fig. 1a and b). ${ }^{22}$ The presence of such high coordinate inorganic centers is thought to confer a large shear modulus upon the framework, though rapid amorphization upon ball-milling is still observed. ${ }^{18}$

The two related MOFs, MIL-140B $\left[\mathrm{ZrO}\left(\mathrm{O}_{2} \mathrm{C}-\mathrm{C}_{10} \mathrm{H}_{6}-\mathrm{CO}_{2}\right)\right]$ and MIL-140C $\left[\mathrm{ZrO}\left(\mathrm{O}_{2} \mathrm{C}-\mathrm{C}_{12} \mathrm{H}_{8}-\mathrm{CO}_{2}\right)\right]$, also collapse relatively quickly upon ball-milling. Respectively crystallizing in the space groups $C c$ and $C 2 / c$, each contains seven-coordinate $\mathrm{Zr}^{4+}$ ions, 
a)

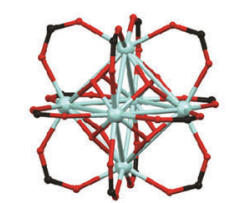

c)

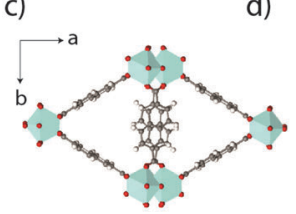

d)
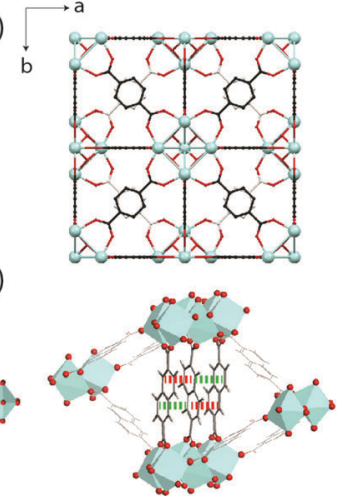

e)

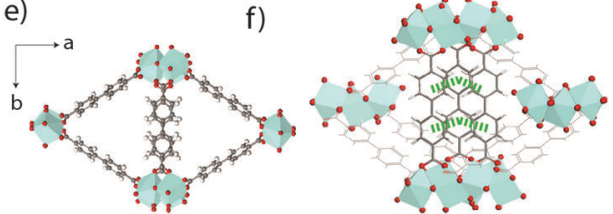

Fig. 1 (a) The $\mathrm{Zr}_{6} \mathrm{O}_{4}(\mathrm{OH})_{4}$ inorganic node present in UiO-66. (b) Unit cell of UiO-66 viewed along a cubic axis. Carbon atoms behind those shown in the foreground are coloured off-white for clarity. (c) The MIL-140B crystal structure proposed in ref. 23 , viewed along the $c$-axis, along with (d) $\pi$-stacking distances along the $c$-axis between the ndc ligands. Red $-4.46 \AA$, green $-3.63 \AA$. (e) The MIL-140C crystal structure proposed in ref. 23 , with (f) corresponding $\pi$-stacking distances (green $-3.94 \AA$ ) along the $c$-axis between the bpdc linkers. $\mathrm{Zr}$ atoms are depicted as light blue polyhedra, $\mathrm{O}$ is red, $\mathrm{C}$ is gray and $\mathrm{H}$ is white.

which are connected to four 2,6-napthalene dicarboxylate (ndc) and 4,4'-biphenyldicarboxylate (bpdc) ligands respectively. Purely inorganic ZrO chains line the $c$-axis of the cells and delimit triangular channels (Fig. 1c), which are larger in MIL-140C due to the larger bpdc organic linker used (Fig. 1e). Whilst $\pi$-stacking along the $c$-axis between all bpdc ligands (i.e. those bisecting the lozenge-shaped channels) is observed in MIL-140C, only $50 \%$ of the corresponding ndc ligands in MIL-140B participate in this stabilization (Fig. 1d and f). ${ }^{23}$

Connections between the mechanical properties of MOFs and their defect content are of interest. UiO-66 has previously been demonstrated to be prone to linker vacancies, ${ }^{22,24}$ the extent of which can be tuned to yield differential adsorption and thermo-mechanical properties. ${ }^{25,26}$ Specifically, recent work has pointed to the direct coordination of $\mathrm{H}_{2} \mathrm{O}$ and solvent molecules to $\mathrm{Zr}^{4+}$ nodes in defective UiO-type structures. ${ }^{27,28}$ Differences between simulated and experimental cell parameters of solvothermally synthesized MIL-140B point towards the presence of defects in this framework, though microwave based syntheses are recorded as producing a defect free material. ${ }^{29,30}$ Potential links between defects and amorphization mechanisms are therefore of much interest, alongside the structure and properties of the resultant amorphous products.

We use infrared spectroscopy and pair distribution function (PDF) measurements to structurally characterize the products of the ball-milling induced collapse of the rigid UiO-66, MIL-140B and MIL-140C frameworks. Density functional theory (DFT) calculations reveal the presence of defects in MIL-140B.
We build defective models, and alongside ${ }^{13} \mathrm{C}$ solid state magic angle spinning (MAS) nuclear magnetic resonance (NMR), use these to suggest the likely nature of the defects in the framework. Overall, we find a quantifiable partial breakage of metal-ligand bonding in each case, though, perhaps surprisingly, the backbone ZrO chains of the MIL-140 frameworks are also damaged in the process. The $\left[\mathrm{Zr}_{6} \mathrm{O}_{4}(\mathrm{OH})_{4}\right]$ clusters of UiO-66 however remain intact.

\section{Experimental}

\section{Materials selection and synthesis}

Samples were synthesized according to previous procedures. ${ }^{18,23}$

\section{Ball milling}

$50 \mathrm{mg}$ of each sample was placed in a $10 \mathrm{~mL}$ stainless steel jar along with one $9 \mathrm{~mm}$ diameter stainless steel ball. The material was then ball-milled for the specified time in a Retsch MM400 grinder mill operating at $20 \mathrm{~Hz}$.

\section{Computational details}

All geometry optimization calculations are based on density functional theory (DFT) and performed using the Vienna $\mathrm{Ab}$ initio Simulation Package (VASP). ${ }^{31}$ Lattice parameters and atomic positions were optimized until the forces on all atoms were smaller than $0.01 \mathrm{eV}^{-1}$ and the SCF convergence criteria is below $1 \times 10^{-5} \mathrm{eV}$. A plane-wave basis set with an energy cutoff of $600 \mathrm{eV}$ was employed, along with the Perdew-BurkeErnzerhof (PBE) exchange-correlation functional. ${ }^{32}$ The longrange weak dispersion interactions were taken into account by different schemes: (1) the DFT-D method of Grimme (DFT-D2 ${ }^{33}$ and DFT-D $3^{34}$ ) and (2) one of the non-local van der Waals functionals of Langreth and Lunquist, namely the optB88-vdW functional. ${ }^{35,36}$ The electron-ion interactions were described by the projector augmented wave (PAW) $\operatorname{method}^{37}$ in the implementation of Kresse and Joubert. ${ }^{38}$ The Brillouin zone integration was performed using a $(1 \times 1 \times 2)$ Monkhorst-Pack grid. $^{39}$

The NMR chemical shift calculations were performed at the VASP optimized geometries using the QUANTUM-ESPRESSO software. $^{40}$ The PBE generalized gradient approximation ${ }^{32}$ was used and the valence electrons were described by norm conserving pseudopotentials in the Kleinman-Bylander form. ${ }^{41}$ The wave functions are expanded on a plane wave basis set with a kinetic energy cut-off of $816 \mathrm{eV}$ and the convergence threshold for the SCF energy was set to $1.36 \times 10^{-9} \mathrm{eV}$. The integrals over the first Brillouin zone are performed at the $\Gamma$ point for the charge density and chemical shift tensor calculations.

The shielding tensor is computed using the GIPAW $^{42}$ approach which permits the reproduction of the results of a fully converged all-electron calculation. The isotropic chemical shift $\delta_{\text {iso }}$ is defined as $\delta_{\text {iso }}=-\left[\sigma-\sigma^{\text {ref }}\right]$ where $\sigma$ is the isotropic shielding and $\sigma^{\text {ref }}$ is the isotropic shielding of the same nucleus in a reference system. In the present case, the comparison between the experimental $\delta_{\text {iso }}$ and calculated $\delta_{\text {iso }}{ }^{13} \mathrm{C}$ chemical 
shift values for carboxylate of benzoic $\operatorname{acid}^{43}\left(\delta_{\text {iso }}=172.0 \mathrm{ppm}\right)^{44}$ allowed to determine $\sigma^{\text {ref }}$ for this nucleus.

\section{Characterization of materials}

Powder X-ray diffraction. Room temperature PXRD data $\left(2 \theta=5-30^{\circ}\right)$ were collected with a Bruker-AXS D8 diffractometer using $\mathrm{Cu} \mathrm{K} \alpha_{1}(\lambda=1.540598 \AA)$ radiation and a LynxEye position sensitive detector in Bragg-Brentano parafocusing geometry.

Nuclear magnetic resonance spectroscopy. Solid state ${ }^{13} \mathrm{C}$ NMR spectra were acquired on a Bruker Avance I, 9.4T spectrometer operating at $400 \mathrm{MHz}$ for ${ }^{1} \mathrm{H}$ and $100 \mathrm{MHz}$ for ${ }^{13} \mathrm{C}$ with the following acquisition parameters: magic angle spinning (MAS) frequency $10 \mathrm{kHz}, 4 \mathrm{~mm}$ outer diameter zirconia rotors, ${ }^{1} \mathrm{H} \pi / 2$ pulse $2.5 \mu \mathrm{s}$, ramped cross polarization from ${ }^{1} \mathrm{H}$ to ${ }^{13} \mathrm{C}$ (CP) $2.5 \mathrm{~ms}$ at $70 \mathrm{kHz}$ matching RF fields, $100 \mathrm{kHz}{ }^{1} \mathrm{H}$ spinal64 decoupling during acquisition, repetition time $30 \mathrm{~s}$, chemical shifts referenced relative to external $\alpha$-glycine methylene signal at $43.1 \mathrm{ppm}$.

Total scattering measurements. Room temperature X-ray data were collected at the I15 beamline at Diamond Light Source, UK, at a wavelength of $\lambda=0.1722 \AA(72 \mathrm{keV})$. Finely powdered samples (crystalline and amorphous) of UiO-66, MIL-140B and MIL-140C were carefully loaded into $1.0 \mathrm{~mm}$ diameter fused silica capillaries. Data were collected in the range $\sim 0.5<Q<\sim 22 \AA^{-1}$ and data from an empty instrument and capillary were also collected for background subtraction. Corrections for background, multiple scattering, container scattering, Compton scattering and absorption were applied using the GudrunX program. ${ }^{45}$ The corrected and normalized reciprocal space data were then converted to the PDFs using Fourier transform within GudrunX.

\section{Results and discussion}

\section{Powder X-ray diffraction and infrared spectroscopy}

Consistent with prior work, ball-milling of crystalline samples of UiO-66 (10 min), MIL-140B (15 min) and MIL-140C (20 min) resulted in the disappearance of Bragg peaks from the powder X-ray diffraction patterns (Fig. 2). We term the products $\mathbf{a}_{\mathbf{m}}$ UiO-66 and $\mathbf{a}_{\mathbf{m}}$ MIL-140C, where the subscript $m$ refers to amorphization by mechanochemical means. An asterisk denotes the retention of some Bragg peaks in the diffraction pattern of MIL-140B after milling ( $\mathbf{a}_{\mathbf{m}}$ MIL-140B*, Fig. 2b inset). Infrared spectroscopy revealed the emergence of a band centered at $c a .1700 \mathrm{~cm}^{-1}$ upon amorphization of the MIL-140 samples, which is assigned to the uncoordinated carbonyl stretching frequency (Fig. 2). An increase in intensity of this band was also noted upon collapse of UiO-66, where uncoordinated bdc ligands within the pores result in a small feature at $1700 \mathrm{~cm}^{-1}$ in the crystalline sample. ${ }^{46}$

\section{Nuclear magnetic resonance spectroscopy}

NMR has proven a valuable tool in the detailed structural characterization of MOFs. ${ }^{4-52}$ The qualitative observation of partial destruction of metal-ligand bonding motivated us to perform solid-state ${ }^{13} \mathrm{C}$ MAS NMR on the compounds.

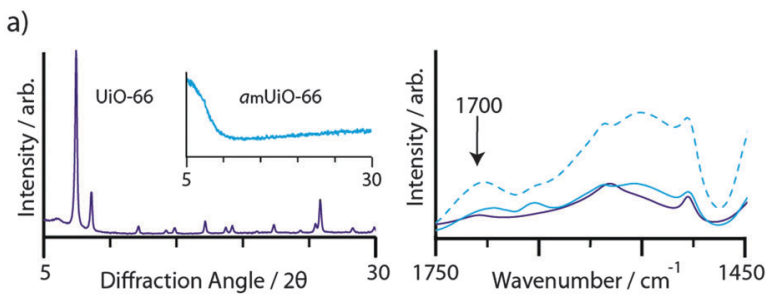

b)
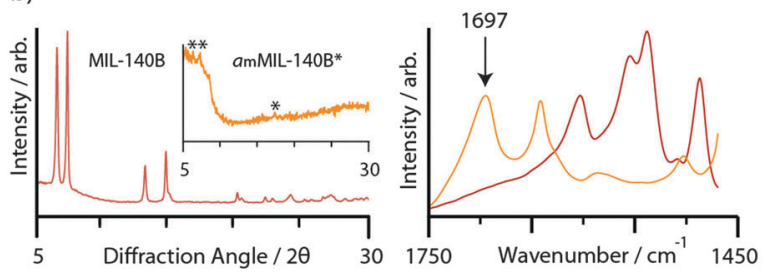

c)
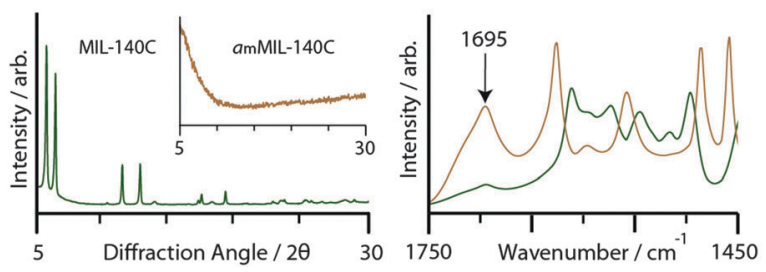

Fig. $2 \mathrm{CuK} \alpha_{1}$ powder $\mathrm{X}$-ray diffraction patterns, and IR spectra, of crystalline and (inset) amorphous samples (left hand plots), complete with IR spectra of the region 1450-1750 $\mathrm{cm}^{-1}$ (right hand plots). (a) UiO-66: dark blue, $\mathbf{a}_{m}$ UiO-66: light blue, $\mathbf{a}_{m}$ UiO-66 after 20 minutes ball milling: broken light blue, (b) MIL-140B: red, $a_{m}$ MIL-140B*: orange, (c) MIL-140C: green, $a_{m}$ MIL-140C: brown.
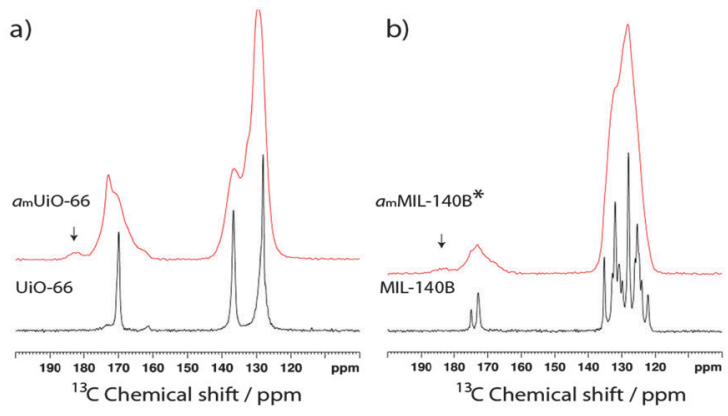

c)

d)
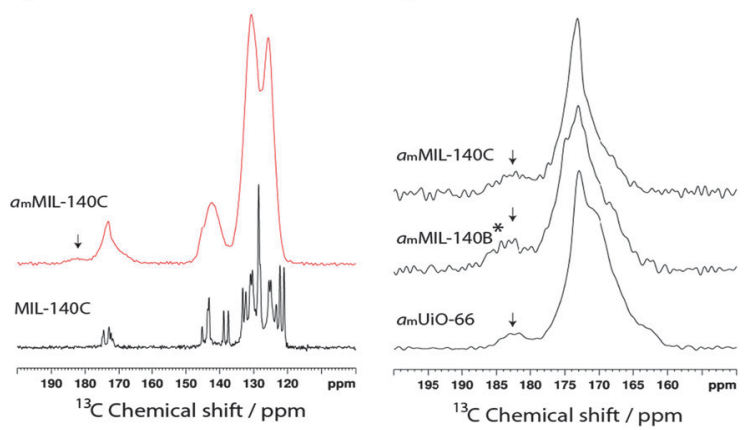

Fig. $3{ }^{13} \mathrm{C}$ MAS NMR spectra of crystalline (black) and amorphous (red) samples of (a) UiO-66, (b) MIL-140B and (c) MIL-140C. (d) Magnified view of the 150-200 ppm region of the amorphous samples. 
The experimental spectrum of UiO-66 (Fig. 3a) contains three peaks. Based on prior work, ${ }^{46}$ resonances at $128 \mathrm{ppm}$ and $137 \mathrm{ppm}$ are assigned to the two types of carbon on the bdc aromatic ring, whilst the carboxylate-binding group gives rise to the signal at $170 \mathrm{ppm}$. The ${ }^{13} \mathrm{C}$ NMR spectrum of MIL-140B (Fig. 3b) is significantly more complicated, containing multiple signals in the 120-140 ppm region and two distinct resonances at $173.5 \mathrm{ppm}$ and $175 \mathrm{ppm}$. A further increase in complexity is noted in the ${ }^{13} \mathrm{C}$ MAS NMR spectrum of MIL-140C (Fig. 3c), which now contains three resonances in the region 170-175 ppm.

Upon amorphization, significant peak broadening of all signals is observed in the experimental spectra, though an indication of retention of the bdc ligand in $\mathbf{a}_{\mathbf{m}} \mathbf{U i O} \mathbf{6 6}$ is given by the two identifiable signals which make up the broad peak at low chemical shift (Fig. 3a). Coalescence of the signals belonging to non-carboxylate carbon atoms in $\mathbf{a}_{\mathbf{m}} \mathbf{M I L}_{\mathbf{- 1 4 0 B}} \mathbf{1}^{*}$ is observed (Fig. 3b), while three distinct features in the $120-145 \mathrm{ppm}{ }^{13} \mathrm{C}$ spectrum of $\mathbf{a}_{\mathbf{m}}$ MIL-140C remain apparent (Fig. 3c). Loss of chemically distinct ligand environments in the MIL-140 frameworks was confirmed by coalescence of carboxylate peaks at $c a$. $170 \mathrm{ppm}$ in each case.

A small additional feature at ca. $182.5 \mathrm{ppm}$ appears upon amorphization for all three samples (Fig. 3d). The higher chemical shift of this peak is consistent with loss of carboxylate coordination to the $\mathrm{Zr}^{4+}$ ions upon structural collapse. Integration traces of the carboxylate signals in the amorphous samples yielded the approximate ratio of this emergent peak to the main peak. In $a_{m}$ UiO-66, the new feature was found to account for $c a .6 .8 \%$ of the total intensity from the carboxylate carbon, suggesting a low degree of $\mathrm{Zr}$-OOC bond breaking. This is raised to $\mathrm{ca}$. $13.2 \%$ and $\mathbf{1 1 . 0 \%}$ respectively in MIL-140B and MIL-140C, implying a higher degree of coordinate bond breaking in these samples upon amorphization.

\section{Non-defective modeling of MIL-140B}

In order to understand and better assign individual features in the experimental ${ }^{13} \mathrm{C}$ NMR spectra of MIL-140B and MIL-140C, DFT calculations were performed using their previously reported crystal structures, ${ }^{23}$ which were derived using a computationally assisted strategy from the crystal structure of MIL-140A (the bdc-based isoreticular structure); the only one solved by Rietveld refinement of X-ray powder diffraction data. ${ }^{23}$ Simulated cell parameters and volumes for MIL-140B and MIL-140C were obtained in the present work upon fully relaxing coordinates and cell parameters, using four different DFT approaches: one with no dispersion correction (PBE), two with dispersion correction using the DFT-D approach of Grimme by means of D2 and D3 corrections (PBE-D2 ${ }^{33}$ and PBE-D3 ${ }^{34}$ ), and one employing one of the non-local van der Waals functionals (optB88-vdW). ${ }^{35,36}$ We first discuss attempts at structural optimization of alternative, non-defective MIL-140B structures, before considering defective MIL-140B models and their relative energetics, and then their respective calculated ${ }^{13} \mathrm{C}$ NMR responses.

Upon comparison of DFT results with the experimental values for MIL-140B (Table 1), all employed DFT schemes converge systematically to a larger cell volume than the
Table 1 Cell parameters of experimental and optimized crystal structures of MIL-140B, MIL-140B( $r$ ) and MIL-140C. MIL-140B(r) refers to a defective model imposing a $180^{\circ}$ rotation around the $b$-axis to ndc linkers (see text for details). PBE-D2, PBE-D3, optB88-vdW represent dispersion corrected schemes. PBE-D3//exp entry refers to a geometry optimization of MIL-140B at the experimental lattice parameters

\begin{tabular}{lllllllll}
\hline & $a(\AA)$ & $b(\AA)$ & $c(\AA)$ & $\alpha\left(^{\circ}\right)$ & $\beta\left(^{\circ}\right)$ & $\gamma\left({ }^{\circ}\right)$ & $V\left(\AA^{3}\right)$ & $E(\mathrm{eV})$ \\
\hline MIL-140B & & & & & & & & \\
Exp. ref. 23 & 26.71 & 13.30 & 7.79 & 90 & 92.56 & 90 & 2763.2 & \\
PBE & 28.05 & 13.49 & 8.02 & 90 & 94.26 & 90 & 3024.7 & \\
PBE-D2 & 28.05 & 13.46 & 7.87 & 90 & 93.40 & 90 & 2964.7 & \\
PBE-D3 & 27.95 & 13.46 & 7.91 & 90 & 93.34 & 90 & 2970.7 & 0 \\
PBE-D3//exp & 26.71 & 13.30 & 7.79 & 90 & 92.56 & 90 & 2763.2 & +1.57 \\
optB88-vdW & 28.00 & 13.44 & 7.89 & 90 & 93.82 & 90 & 2963.3 & 0
\end{tabular}

MIL-140B(r)

$\begin{array}{llllllll}\text { PBE-D2 } & 27.65 & 13.41 & 7.84 & 89.32 & 90.12 & 88.86 & 2906.1\end{array}$

$\begin{array}{lllllllll}\text { PBE-D3 } & 27.56 & 13.41 & 7.88 & 89.50 & 90.34 & 88.81 & 2909.8 & -0.38\end{array}$ $\begin{array}{lllllllll}\text { optB88-vdW } & 27.28 & 13.38 & 7.85 & 91.06 & 88.66 & 88.16 & 2864.8 & -0.47\end{array}$

\begin{tabular}{llllllll}
\hline MIL-140C & $a(\AA)$ & $b(\AA)$ & $c(\AA)$ & $\alpha\left(^{\circ}\right)$ & $\beta\left({ }^{\circ}\right)$ & $\gamma\left({ }^{\circ}\right)$ & $V\left(\AA^{3}\right)$ \\
\hline Exp. ref. 23 & 31.03 & 15.51 & 7.82 & 90 & 93.26 & 90 & 3756.6 \\
PBE & 31.52 & 15.63 & 7.97 & 90 & 87.06 & 90 & 3918.3 \\
PBE-D2 & 31.29 & 15.58 & 7.78 & 90 & 89.67 & 90 & 3794.7 \\
PBE-D3 & 31.25 & 15.59 & 7.82 & 90 & 89.32 & 90 & 3810.9 \\
optB88-vdW & 31.16 & 15.59 & 7.78 & 90 & 89.90 & 90 & 3778.8
\end{tabular}

experimental one $(7.5 \%$ error). This mainly emanates from the recurrent overestimation of the lattice constant $a$ found at $\sim 28$ schemas (4.8\% error), while $b$ and $c$ are predicted with excellent accuracy (within $1.5 \%$ error). This cell expansion occurs when dispersion corrections are omitted (PBE entry), and is surprisingly maintained when they are taken into account, a result which is not sensitive to the methodology by which the dispersion is calculated (PBE-D2, -D3 and optB88-vdW entries). A further geometry optimization of MIL-140B, constraining its cell parameters to the experimentally determined values (PBE-D3//exp entry), reveals it is much less stable by $1.57 \mathrm{eV}$ than its relaxed MIL-140B counterpart (PBE-D3 entry), pointing towards an inconsistency between the structural model used and the experimentally determined cell parameters. Expectedly, the simulated ${ }^{13} \mathrm{C}$ spectrum of MIL-140B is in very poor agreement with the experimental one, in both regions of carboxylate and aromatic carbons (Fig. S1a, ESI $\dagger$ ), supporting a hypothesis of a different, or defective MIL-140B structure not captured in the initial model of ref. 23.

The situation is markedly different with MIL-140C, with excellent predictions from DFT structure optimizations (Table 1 and Fig. S2, ESI $\dagger$ ). While dispersion correction-free DFT calculations slightly overestimate the a cell parameter (1.6\% error) and cell volume, $V$ (4.3\% error), all dispersioncorrected DFT calculations yield excellent agreement when compared to experiment, particularly the optB88-vdW entry with errors reduced to $0.4 \%$ and $0.6 \%$ for $a$ and $V$, respectively. As in all MIL-140B calculations, the $c$ parameter is systematically very well predicted. This reflects the structural rigidity associated with the inorganic subunit of the zirconium oxide chains along that direction. Taking the dispersion effects into account improves the simulation of the MIL-140C crystal structure and 
highlights the importance of the $\pi$-stacking stabilizing interactions along the $c$-axis, which take place with the involvement of all bpdc ligands at regular center-to-center distances of $3.9 \AA$ (Fig. 1f). The simulated NMR spectra provide significantly better agreement with observed NMR shifts, supporting a consistent initial structural model (Fig. S2, ESI $\dagger$ ).

The failure of DFT calculations to predict the correct cell volume and lattice parameters for MIL-140B reveals that its stabilization at the smaller observed cell parameters emanates from additional structural features. This together with NMR discrepancies prompted us to an in-depth investigation of the structure and defects in MIL-140B, as a case study.

\section{Enhanced $\pi$-stacking in MIL-140B}

A first variant of the reported MIL-140B structure, hereby referred to as $\mathbf{M I L}-\mathbf{1 4 0 B}(\mathbf{r})$, where (r) indicates the partial rotation of linkers, was therefore constructed by imposing a $180^{\circ}$ rotation around the $b$-axis to the ndc linkers not participating in the $\pi$-stacking (Fig. 4a). The resultant MIL-140B(r) model is hence one in which a full $\pi$-stacking of ndc linkers along the $c$-axis occurs. As a result, the fully relaxed MIL-140B(r) model is $0.38 \mathrm{eV}$ lower in energy than the parent MIL-140B, compared at the same level of theory (Table 1, PBE-D3 entry). This stabilization is assigned mainly to the now enhanced $\pi$-stacking along $c$. In addition, the sole rotation of these ndc linkers induces a large contraction along the $a$-axis, of $0.4-0.7 \AA$ depending on the level of theory, with an error reduced to $2-3 \%$.

\section{Addition of uncoordinated $\mathrm{H}_{2} \mathrm{O}$}

While being closer to experimental findings, MIL-140B(r) still exhibits overestimated cell parameters. Given recent reports of the defects in UiO-materials being caused by $\mathrm{H}_{2} \mathrm{O}$ or solvent molecules, ${ }^{27,53}$ we thus further constructed several non-defective structures, where low concentrations of water are introduced as adsorbed molecules. Table 2 summarizes the optimized cell parameters and their relative energies obtained at the PBE-D3 level of theory.
Table 2 Optimized cell parameters (PBE-D3 level of theory) of MIL-140B defective variants containing different amount of adsorbed or coordinated water molecules per unit cell. Energies are given in eV with respect to the structures with adsorbed (uncoordinated) water molecules. ' $r$ ' refers to models constructed with rotated linkers for $\pi$-stacking enhancement while " 0 " refers to models constructed from the parent MIL-140B. A, B, $C$ and $D$ refer to the various defect pathways $(a, b, c, d)$ in Fig. 5. 'e' refers to models with extended coordination of water molecules along the a-axis

$$
a(\AA) \quad b(\AA) \quad c(\AA) \quad \alpha\left({ }^{\circ}\right) \quad \beta\left(\left(^{\circ}\right) \quad \gamma\left({ }^{\circ}\right) \quad V\left(\AA^{3}\right) \quad E(\mathrm{eV})\right.
$$

\section{Uncoordinated water}

$\begin{array}{lllllllll}\text { MIL-140B } \mathbf{H}_{2} \mathbf{O} & 27.84 & 13.47 & 7.89 & 90.57 & 92.79 & 90.02 & 2957.5 & 0\end{array}$

$\begin{array}{llllllllll}\text { MIL-140B-2H } & \mathrm{O} & 27.82 & 13.48 & 7.90 & 89.96 & 93.01 & 90.54 & 2955.5 & 0\end{array}$

$\begin{array}{llllllllll}\text { MIL-140B(r). } H_{2} \mathbf{O} & 27.52 & 13.42 & 7.87 & 89.49 & 90.15 & 88.94 & 2905.4 & -0.35\end{array}$ $\begin{array}{lllllllll}\text { MIL-140B(r) } \cdot 2 \mathrm{H}_{2} \mathrm{O} & 27.51 & 13.44 & 7.86 & 89.26 & 90.24 & 89.15 & 2905.4 & -0.37\end{array}$

Coordinated water

$\mathbf{A}_{\mathbf{r}}$

$\mathbf{A}_{\mathbf{r e}}$

$\mathbf{A}_{\mathbf{0}}$

$\mathbf{A}_{\mathbf{0 e}}$

$\mathbf{B}_{\mathbf{r}}$

$\mathbf{B}_{\mathbf{0}}$

$\mathrm{C}_{\mathbf{0}}$

$\begin{array}{llllllll}27.28 & 13.42 & 7.86 & 90.07 & 88.28 & 89.20 & 2875.1 & +0.02\end{array}$ $\begin{array}{lllllllll}26.63 & 13.45 & 7.83 & 90.36 & 84.44 & 89.91 & 2789.4 & +0.40\end{array}$ $\begin{array}{lllllllll}27.79 & 13.46 & 7.87 & 90.34 & 92.13 & 90.52 & 2944.2 & +0.21\end{array}$ $\begin{array}{llllllll}27.56 & 13.49 & 7.85 & 90.79 & 90.12 & 91.10 & 2918.8 & +0.37\end{array}$ $\begin{array}{lllllllll}27.40 & 13.41 & 7.85 & 90.67 & 89.54 & 87.65 & 2882.5 & +0.26\end{array}$ $\begin{array}{lllllllll}27.69 & 13.47 & 7.85 & 89.43 & 92.26 & 89.51 & 2925.6 & +0.54\end{array}$ $\begin{array}{lllllllll}27.77 & 13.46 & 7.85 & 90.18 & 93.30 & 89.41 & 2930.2 & +0.82\end{array}$

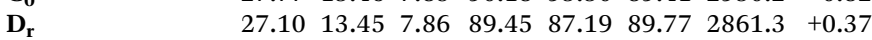

Two hydrated models were derived from MIL-140B and MIL-140B(r), respectively (labelled “. $\mathrm{H}_{2} \mathrm{O}$ ”), by adding one adsorbed water molecule per cell (Fig. $4 \mathrm{~b}$ and d). Upon full relaxation, the water molecule preferentially forms hydrogen bonds with two carboxyl oxygen atoms (1.99 and $1.95 \AA$ ) of two neighbouring ndc linkers stacked along $c$, with minor change in cell volumes. The rotated hydrated model was found to be of lower energy (by $0.35 \mathrm{eV}$ ) than the non-rotated one, which is ascribed entirely due to the enhanced $\pi$-stacking in MIL-140B(r) (see Table 1). Addition of a second uncoordinated water to both models (labelled $2 \mathrm{H}_{2} \mathrm{O}$ ), to a site at the opposite end of the organic linker to the first molecule, did not result in any cell modification nor further stabilization.

\section{Defect modelling}

$\mathrm{H}_{2} \mathrm{O}$ coordination to $\mathrm{Zr}$ combined with linker displacement. In further models, $\mathrm{H}_{2} \mathrm{O}$ was allowed to coordinate to $\mathrm{Zr}^{4+}$ ions,
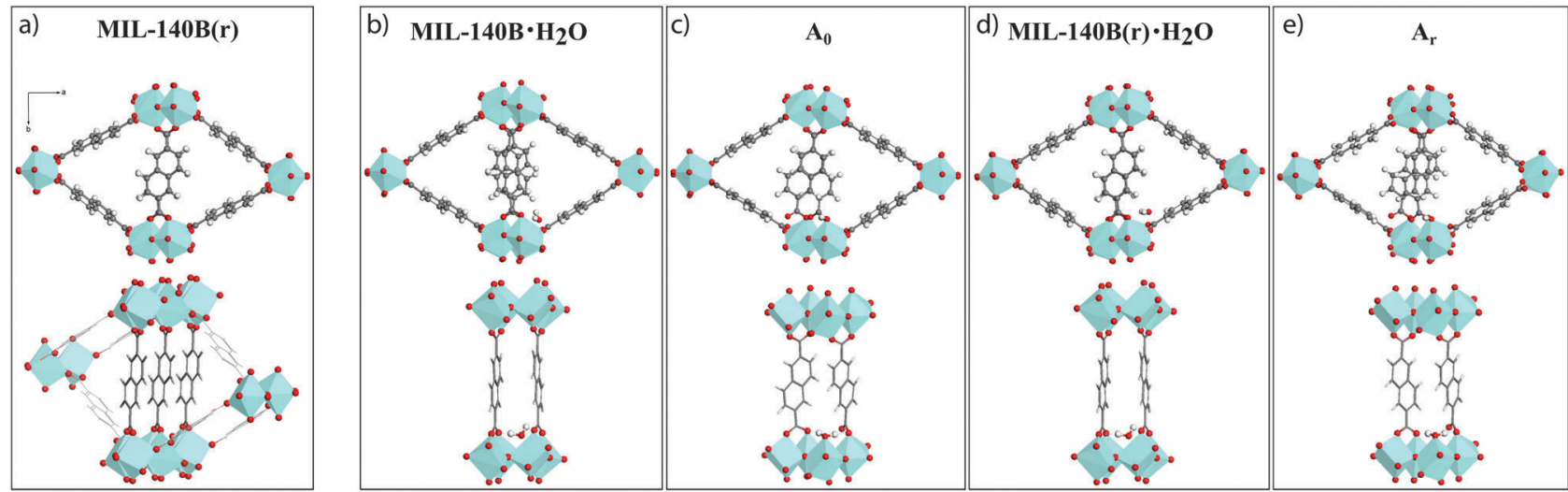

Fig. 4 Crystal structure of MIL-140B(r), formed by rotating $50 \%$ of the ndc linkers which lie along the $a$-axis, around the $b$-axis by $180^{\circ}$. Structures of

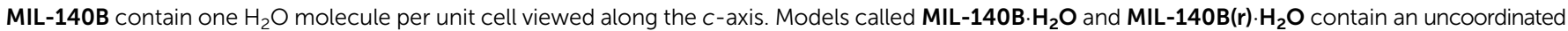
water molecule, while $\mathbf{A}_{\mathbf{0}}$ and $\mathbf{A}_{\mathbf{r}}$, are defective models and are built with a $\mathrm{H}_{2} \mathrm{O}$ molecule coordinates directly to a $\mathrm{Zr}$-center. The latter displaces the linker which becomes monodentate on one its carboxylate end. $\mathrm{Zr}$ atoms are depicted as light blue polyhedra, $\mathrm{O}$ is red, $\mathrm{C}$ is gray and $\mathrm{H}$ is white. 
forming defective MIL-140B structures. Four possible defect incorporation pathways, (a)-(d) were considered (Fig. 5), respectively leading to models A-D (Fig. S3, ESI $\dagger$ ). Models arising from the original MIL-140B structure are given the subscript ' 0 ', and those arising from MIL-140B(r), are given the subscript ' $\mathrm{r}$ ', e.g. $\mathbf{A}_{\mathbf{0}}$ and $\mathbf{A}_{\mathbf{r}}$ respectively for pathway ' $a$ '.

In pathway 'a', one end of an ndc linker was displaced into a monodentate state, allowing coordination of one $\mathrm{H}_{2} \mathrm{O}$ molecule to the newly created defect site. Upon relaxation, the chemisorbed water remained bound to $\mathrm{Zr}$ and established hydrogen bonds with its two surrounding carboxyl oxygen atoms (1.80 ̊). Interestingly, model $\mathbf{A}_{\mathbf{r}}$ is isoenergetic to the relative ground state $\mathbf{M I L - 1 4 0 B} \cdot \mathbf{H}_{\mathbf{2}} \mathrm{O}$ structure $(0.02 \mathrm{eV})$ : the energy penalty for breaking $\mathrm{Zr}-\mathrm{O}$ (linker) bond and altering the $\pi$-stacking is compensated by the coordination of the water molecule to $\mathrm{Zr}$. In addition, unlike the (noncoordinating) adsorption of water, the chemisorption of water on the $\mathrm{Zr}$-center in $\mathbf{A}_{\mathbf{r}}$ leads to a significant cell contraction along $a$ (up to $\sim 0.3 \AA$ ) when compared to the water-free model, making $\mathbf{A}_{\mathbf{r}}$ a promising defective model candidate.

Extension of this defect with a second coordinated $\mathrm{H}_{2} \mathrm{O}$ molecule along the $a$-axis (model $\mathbf{A}_{\mathbf{r e}}$ ) induces a relatively low energetic penalty $(+0.40 \mathrm{eV})$. More importantly, this results in a further cell contraction of this defective MIL-140B model along the $a$ lattice constant $(a=26.63 \AA$ ), in excellent agreement with the experimentally determined value for the MIL-140B structure of 26.71 A. Identical treatment of MIL-140B- $\mathbf{H}_{2} \mathbf{O}$, the non-rotated system, gave rise to models $\mathbf{A}_{\mathbf{0}}$ and $\mathbf{A}_{\mathbf{0 e}}$, which are only $0.21 \mathrm{eV}$ and $0.37 \mathrm{eV}$ higher in energy than the reference ground state of MIL-140B with uncoordinated water molecule, respectively, with however poor agreement in lattice parameters.

Turning to defect $\mathrm{B}$, we considered translation of the entire ndc linker induced by the chemisorption of two water molecules on the opposite Zr-centers (pathway 'b' in Fig. 5). As a result, the

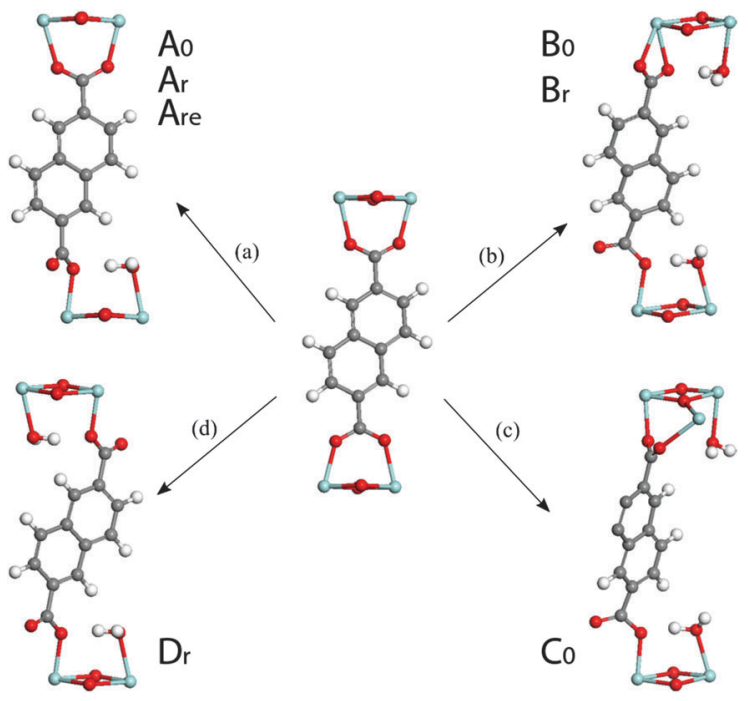

Fig. 5 Formation of different types of defective structures upon direct binding of water on a $\mathrm{Zr}$-center. The names of the defective models derived from each pathway are included for clarity. $\mathrm{Zr}$ - light blue, $\mathrm{O}$ - red, C - gray, $\mathrm{H}$ - white. linker becomes monodentate on one side and bidentate on the other. The resultant models, $\mathbf{B}_{\mathbf{r}}$ and $\mathbf{B}_{\mathbf{0}}$, are +0.26 and $+0.54 \mathrm{eV}$ higher in energy than the reference model.

A third type of defect yielded model $\mathbf{C}_{\mathbf{0}}$ (pathway 'c', in Fig. 5). Whilst the defect resembles that in pathway ' $b$ ', the linker binds to two neighbouring Zr-centers along the $c$ direction. This structure was deemed unfavourable by $+0.82 \mathrm{eV}$ with respect to the reference defect-free model MIL-140B-2 $\mathbf{H}_{2} \mathrm{O}$.

A fourth defect structure, modelled by following pathway 'd' in Fig. 5, yields $\mathbf{D}_{\mathbf{r}}$. In this structure both ends of an ndc linker were displaced into a monodentate position, allowing coordination of a $\mathrm{H}_{2} \mathrm{O}$ molecule to each of the two newly created defective $\mathrm{Zr}$ sites. It can form with an energy cost of $0.37 \mathrm{eV}$ and shows significant shrinking of the lattice vector $a$ to $27.10 \AA$.

Overall, this series of calculations tend to suggest that the formation of defects in MIL-140B may occur through the coordination of water molecules to $\mathrm{Zr}$ centers together with the displacement of the linker and that such defects are associated with relatively low energy penalties. They also indicate that defect pathways allowing the enhancement of $\pi$-stacking of ndc linkers along $c$ direction might be favoured, exemplified in ' $r$ ' type models.

Comparison of predicted ${ }^{13} \mathrm{C}$ NMR shifts from defective models. ${ }^{13} \mathrm{C}$ NMR chemical shift calculations were performed on our defective MIL-140B variants in order to evaluate the accuracy of these models with respect to available experimental data. Calculation of the ${ }^{13} \mathrm{C}$ NMR chemical shifts for the MIL-140B(r) model yielded significantly better agreement with the experimentally observed shifts than those attained directly from MIL-140B (Fig. S1b, ESI $\dagger$ ). This is most notable in the increased complexity of the splitting pattern in the aromatic carbon region that covers more consistently the whole range of observed peaks. The concordance of such splitting between the experimental data and this $\mathbf{M I L - 1 4 0 B ( r ) ~ m o d e l ~ s u g g e s t s ~}$ that rotation of ndc linkers might indeed occur so as to favor $\pi$-stacking locally. This improved agreement in the $120-140 \mathrm{ppm}$ aromatic region is retained in hydrated models, i.e. $\mathbf{A}_{\mathbf{r e}}, \mathbf{B}_{\mathbf{r}}$ and $\mathbf{D}_{\mathbf{r}}$, in which $\mathrm{H}_{2} \mathrm{O}$ is introduced directly to the $\mathrm{Zr}$ coordination sphere. The region of the NMR spectra attributed to carboxylate shifts (170-190 ppm) of $\mathbf{A}_{\mathbf{r e}}, \mathbf{B}_{\mathbf{r}}$ and $\mathbf{D}_{\mathbf{r}}$, however, shows a lower level of agreement with the experimental spectra of MIL-140B with a large dispersion of the calculated values compared to the experimental ones.

Whilst possible, defect-incorporating models $\left(\mathbf{A}_{\mathbf{r e}}, \mathbf{B}_{\mathbf{r}}\right.$ and $\left.\mathbf{D}_{\mathbf{r}}\right)$, for the reported MIL-140B structure have been suggested, it is equally interesting that some of the features in the predicted NMR shifts agree well with those of $\mathbf{a}_{\mathbf{m}}$ MIL-140B. The range of chemical shifts across the spectra observed shows excellent agreement with those for the amorphized MIL-140B sample. The predicted ${ }^{13} \mathrm{C}$ NMR spectrum of model $\mathbf{B}_{\mathbf{r}}$ however, is the only one to exhibit a peak in the region 185-190 ppm, which is identified to be a fingerprint of one carboxylate end being bound in a bidentate fashion to $\mathrm{Zr}^{4+}$. Since this is closely reminiscent of the feature which appears upon amorphization, it provides some evidence as to the introduction of defects upon ball-milling of the structure. 


\section{Pair distribution function studies}

Analysis of the pair distribution function, or the weighted histogram of atom-atom distances, ${ }^{54}$ of amorphous inorganic zeolites $^{55}$ and MOFs, ${ }^{12}$ has in the past yielded useful information on the chemical structure of complex amorphous systems. Room temperature total scattering data were therefore collected on crystalline and amorphous samples using synchrotron radiation $\left(\lambda=0.1722 \AA, Q_{\max }=22 \AA^{-1}\right)$. The resultant structure factors $S(Q)$ (Fig. S4-S6, ESI $\dagger$ ) of $\mathbf{a}_{\mathbf{m}}$ UiO-66 and $\mathbf{a}_{\mathbf{m}}$ MIL-140C are devoid of Bragg peaks, confirming the amorphous sample nature. Expectedly, that of $\mathbf{a}_{\mathbf{m}}$ MIL-140B* contains some features due to Bragg scattering. After suitable corrections using the GudrunX software, ${ }^{45}$ the data were converted to the corresponding PDFs by Fourier transform. ${ }^{56}$

Due to the difficulties in obtaining reliable data below $\sim 1 \AA$ from X-ray total scattering instruments, the first peak in the PDF of crystalline UiO-66 belonging to a physical atom-atom correlation appears at $\sim 1.3 \AA$, which corresponds to $\mathrm{C}-\mathrm{C}$ or C-O direct linkages (A, Fig. 6a). Other features below $6 \AA$ (B-F) are assigned to various $\mathrm{Zr}-\mathrm{Zr}$ and $\mathrm{Zr}-\mathrm{O}$ inter-cluster separations. At longer distances, overlapping contributions from similarly spaced $\mathrm{Zr}-\mathrm{C}$ atom pairs results in peak broadening and renders precise assignment of the features at $\sim 6.5 \AA$ and $\sim 8.6 \AA$ challenging. The large relative scattering cross-section of $\mathrm{Zr}$ results in sharp features above $10 \AA(\mathrm{G}-\mathrm{K})$ in the PDF of UiO-66, which can be ascribed to $\mathrm{Zr}$ atom pairs joined through a bdc linker (Fig. 6b).

Below $6 \AA$, the PDF of $\mathbf{a}_{\mathbf{m}}$ UiO-66 is very similar to UiO-66, with peaks $\mathrm{A}-\mathrm{F}$ appearing invariant in position between the two and thus confirming the presence of the $\mathrm{Zr}_{6} \mathrm{O}_{4}(\mathrm{OH})_{4}$ structural building unit in $\mathbf{a}_{\mathbf{m}}$ UiO-66. Coalescence of the double peaks centered at $\sim 6.5 \AA$ and $\sim 8.6 \AA$ occurs upon amorphization,

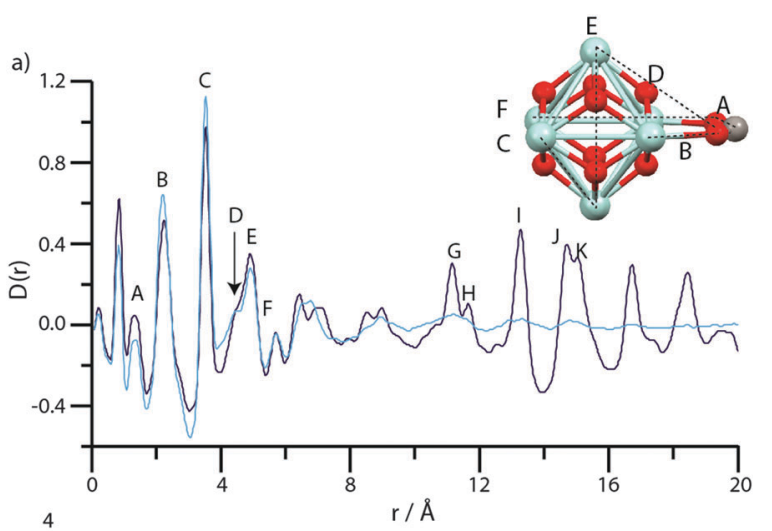

b)

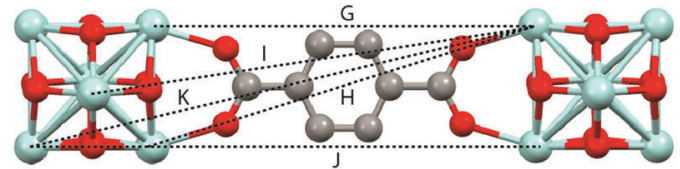

Fig. 6 (a) PDF data for UiO-66 (dark blue) and $\mathbf{a}_{\mathbf{m}}$ UiO-66 (light blue). A-F labels of peaks below $8 \AA$ correspond to the indicated correlations in the $\mathrm{Zr}_{6} \mathrm{O}_{4}(\mathrm{OH})_{4}$ cluster (inset). (b) Two $\mathrm{Zr}_{6} \mathrm{O}_{4}(\mathrm{OH})_{4}$ units linked by a bdc ligand, and some of the significant distances corresponding to the longer $r$ features $(\mathrm{G}-\mathrm{K})$ in (a). $\mathrm{Zr}$ - light blue, $\mathrm{O}$ - red, $\mathrm{C}$ - gray, $\mathrm{H}$ - omitted. yielding two broad features in the PDF of $\mathbf{a}_{\mathbf{m}}$ UiO-66. The reduction in intensity and severe broadening of these peaks, and those labelled G-K, in $\mathbf{a}_{\mathbf{m}}$ UiO-66 is indicative of the loss of long range-order of the framework. The presence however of some intensity does suggest at least the partial retention of the structural linkage, though substantial changes to $\mathrm{Zr}-\mathrm{Zr}$ correlations would be expected if only one $\mathrm{Zr}-\mathrm{O}$ bond were to break. The observable extent of order in $\mathbf{a}_{\mathbf{m}} \mathbf{U i O} \mathbf{6 6}$ may extend beyond $15.9 \AA$, though this is the last distance at which correlations can be unambiguously assigned to $\mathrm{Zr}-\mathrm{Zr}$ atoms separated by the organic linker.

The PDF of MIL-140B (Fig. 7a) contains the expected peaks (L-N) belonging to nearest neighbour $\mathrm{C}-\mathrm{C} / \mathrm{C}-\mathrm{O}, \mathrm{Zr}-\mathrm{O}$ and $\mathrm{Zr}-\mathrm{Zr}$ distances at $c a$. $1.3 \AA, 2 \AA$ and $3.3 \AA$, whilst at further distances below $8 \AA$ (O-R), non nearest neighbour correlations of $\mathrm{Zr}-\mathrm{Zr}$ and $\mathrm{Zr}-\mathrm{O}$ atoms also elicit sharp features. These corresponding chemical distances relating to $\mathrm{L}-\mathrm{R}$ are indicated in the inset of Fig. 7a, and all relate to the inorganic ZrO backbone chain. Sharp features associated with crystalline order continue to be observed in the PDF of MIL-140B to distances up to $20 \AA$, as expected. Key features (S-U) at these longer $r$ values agree well with $\mathrm{Zr}-\mathrm{Zr}$ distances separated by the 2,6-ndc linker (Fig. 7b).

Features $\mathrm{L}$ and $\mathbf{M}$ are located in the same position in the PDF of $\mathbf{a}_{\mathbf{m}}$ MIL-140B* (Fig. 7a), though N, which corresponds to the nearest $\mathrm{Zr}-\mathrm{Zr}$ distance in the inorganic backbone, appears to lengthen from $3.3 \AA$ to $3.5 \AA$ upon amorphization. Another noticeable change in the PDF of $\mathbf{a}_{\mathbf{m}}$ MIL-140B* is the loss in intensity of peaks $\mathrm{O}-\mathrm{Q}$, which correspond to non-nearest neighbour $\mathrm{Zr}$ and $\mathrm{O}$ distances in the $\mathrm{ZrO}$ backbone chains. Somewhat surprisingly, the peak at $7.8 \AA$, labelled R, disappears entirely on going from MIL-140B to $\mathbf{a}_{\mathbf{m}}$ MIL-140B*, suggesting the rigid $\mathrm{ZrO}$ inorganic chain no longer remains intact when longer $\mathrm{Zr}-\mathrm{Zr}$ correlations are considered. Indeed, changes are apparent at even shorter Zr-Zr length scales, with substantial deterioration of the intensity of the $\mathrm{Zr}-\mathrm{O}-\mathrm{Zr}(\mathrm{O})$ peak intensity at $4.5 \AA$, which suggests that some $\mathrm{Zr}-\mathrm{O}$ bonds have been broken during the ball-milling process, causing the chain to twist. Given this partial destruction of the continuous $\mathrm{ZrO}$ backbone, it is surprising that pair correlations relating to $\mathrm{Zr}$ atoms separated by the organic linker $(\mathrm{S}, \mathrm{T}$ and $\mathrm{U})$ persist in $\mathbf{a}_{\mathbf{m}}$ MIL-140B* ${ }^{*}$, with some degree of correlated order extending to $c a .15 .9 \AA$ A. Above this distance, the PDF of $\mathbf{a}_{\mathbf{m}} \mathbf{M I L - 1 4 0 \mathbf { B } ^ { * } \text { is }}$ featureless, in sharp contrast to its crystalline counterpart.

The near-identical nature of the MIL-140C framework, aside from the slightly longer organic linker, led to the labelling of corresponding distances in the PDFs with the same notation as that used in the MIL-140B PDF. Similar differences between amorphous and crystalline frameworks are observed in the PDFs of MIL-140C and $\mathbf{a}_{\mathbf{m}}$ MIL-140C (Fig. 7c and d). In particular, the same lengthening of nearest $\mathrm{Zr}-\mathrm{Zr}$ distances $(\mathrm{N})$ upon amorphization is witnessed. In addition, very similar reductions in the intensity of the peak belonging to nearest neighbour $\mathrm{Zr}-\mathrm{O}$ correlations at $4.5 \AA(\mathrm{O})$ are also observed whilst there is very little intensity in further $\mathrm{Zr}-\mathrm{O}$ correlations (P-R).

This observation provides confidence that the $\mathrm{ZrO}$ backbone shared by both MIL-140B and MIL-140C, undergoes significant 
a)

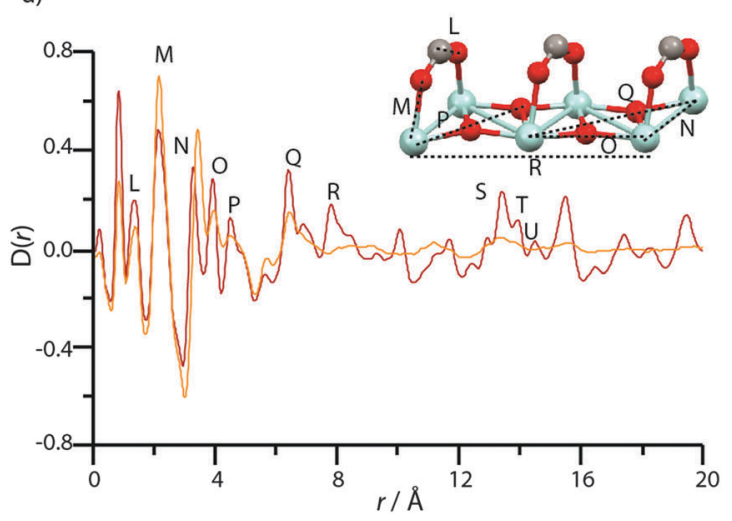

b)

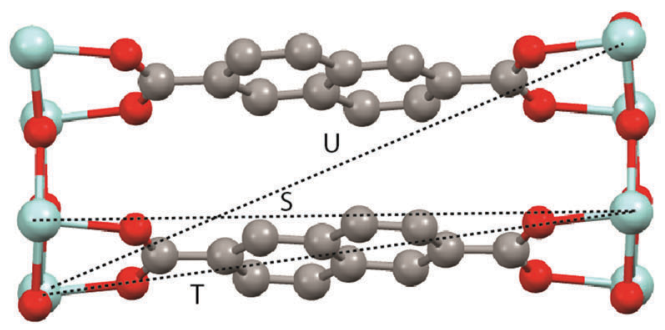

c)

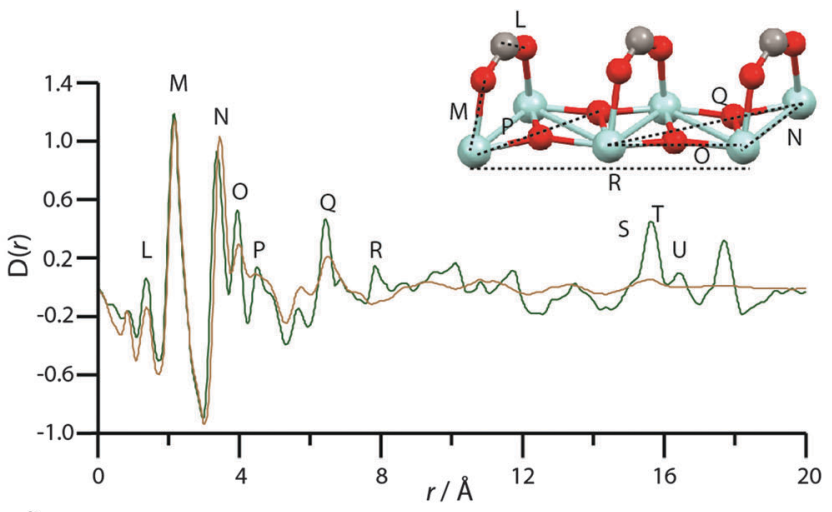

d)

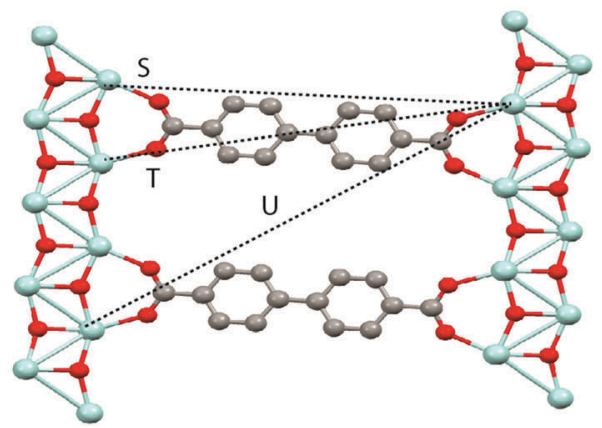

Fig. 7 (a) PDF data for MIL-140B and $\mathbf{a}_{\mathbf{m}}$ MIL-140B*. Labels of peaks below $8 \AA$ correspond to the indicated correlations in the ZrO inorganic chains (inset). (b) Two ZrO chains linked by 2,6-ndc, and the distances corresponding to the longer $r$ features in (a). (c) PDF data for MIL-140C and $\mathbf{a}_{\mathbf{m}}$ MIL-140C. Labels of peaks below $8 \AA$ A correspond to the indicated correlations in the ZrO inorganic chains, as in MIL-140B (inset). (d) Two ZrO chains linked by bpdc, and the distances corresponding to the longer $r$ features in (a). $\mathrm{Zr}$ - light blue, $\mathrm{O}$ - red, $\mathrm{C}$ - gray, $\mathrm{H}$ - omitted. To facilitate assignment of features, partial PDFs were calculated using the PDFgui software (Fig. S7-S9, ESI $\dagger$ ). ${ }^{57}$ All PDFs of crystalline species are, as expected, dominated by correlations involving $\mathrm{Zr}$, due to the larger $\mathrm{X}$-ray scattering cross section of $\mathrm{Zr}$ relative to $\mathrm{C}, \mathrm{O}$ and $\mathrm{H}$.

distortion during ball-milling, though some order persists in the PDF of $\mathbf{a}_{\mathbf{m}}$ MIL-140C, to $17.6 \AA$ ( $\mathrm{S}, \mathrm{T}$ and U). These distances, as in $\mathbf{a}_{\mathbf{m}}$ MIL-140B* ${ }^{*}$, correspond to two $\mathrm{Zr}$ atoms separated by the larger bpdc organic linker (Fig. 7d).

\section{Conclusions}

The results further contribute to the area of non-crystalline metal-organic frameworks and provide insight into the relationship between defects and amorphization. We have identified possible modes of defect incorporation into the structure of MIL-140B; defects investigated include coordinated water to $\mathrm{Zr}$ centers combined with linker displacement. Such defective models provide significantly better agreement with the experimentally observed structural cell parameters than the defect free ones. DFT calculations of the chemical shifts of some models also show similar features to those witnessed experimentally upon amorphization of MIL-140B. We anticipate that the occurrence of such defects might be applicable to other MOFs, given the prevalence of carboxylate linkers in this family.

In addition to solid state NMR, we have used pair distribution function analysis to show that the amorphization of the prototypical UiO-66 framework proceeds via partial breakage of $\mathrm{Zr}$-carboxylate bonds, though the rigid $\mathrm{Zr}_{6} \mathrm{O}_{4}(\mathrm{OH})_{4}$ inorganic building unit appears to remain intact. This is in stark contrast to MIL-140B and MIL-140C, where in addition to metal-carboxylate bond breaking, the inorganic backbone is also heavily damaged during the ball-milling process. This mechanism bears a large similarity to the changes seen in the ball-milling of zeolites, where $\mathrm{M}-\mathrm{O}(\mathrm{M}=\mathrm{Si}, \mathrm{Al})$ bonds are observed to be broken, ${ }^{58}$ whilst the inorganic distortions are to be expected given that pure zirconia undergoes phase transitions and eventual amorphization when subjected to ball-milling. ${ }^{59}$

The different behaviour of the two inorganic units is ascribed to the larger interconnected nature of the inorganic clusters in UiO-66, where $24 \mathrm{Zr}-\mathrm{O}$ bonds hold the unit together. This is in contrast to the ZrO chains of the MIL-140 frameworks, where in a unit containing the same number of $\mathrm{Zr}$ ions, only $16 \mathrm{Zr}-\mathrm{O}$ bonds hold the chain together. Whilst structural defects will also play a role in determining mechanical stability, the research here may be combined with increasing metal-ligand bond strengths, ${ }^{20}$ to yield 'strong' MOFs capable of resisting external stresses.

\section{Acknowledgements}

The manuscript was written through contributions of all authors. TDB conceived the initial project. TDB acknowledges Trinity Hall (University of Cambridge) and Professor Anthony K. Cheetham for use of lab facilities. D. G. R. acknowledges the UK MRC for financial support. We thank Diamond Light Source 
for access to beamline I15 (EE9691) that contributed to the results presented here, and Philip A. Chater and Andrew Cairns for assistance with data collection. T. K. T. and C. M. D. thank the French National Research Agency (ANR project: HOPFAME ANR-13-BS07-0002-01) and the Foundation de l'Orangerie for funding. The calculations have been performed using the HPC resources from GENCI (CINES/TGCC/IDRIS) through Grant (2015-097343 and -091461). B. B., B. V. d. V. and D. D. V. gratefully acknowledge the FWO for funding (aspirant grant).

\section{Notes and references}

1 H. Furukawa, K. E. Cordova, M. O’Keeffe and O. M. Yaghi, Science, 2013, 341, 974-986.

2 J. E. Mondloch, M. J. Katz, W. C. Isley III, P. Ghosh, P. Liao, W. Bury, G. W. Wagner, M. C. Hall, J. B. DeCoste, G. W. Peterson, R. Q. Snurr, C. J. Cramer, J. T. Hupp and O. K. Farha, Nat. Mater., 2015, 14, 512-516.

3 T. D. Bennett and A. K. Cheetham, Acc. Chem. Res., 2014, 47, 1555-1562.

4 S. R. Batten, N. R. Champness, X. M. Chen, J. GarciaMartinez, S. Kitagawa, L. Ohrstrom, M. O'Keeffe, M. P. Suh and J. Reedijk, CrystEngComm, 2012, 14, 3001-3004.

5 T. D. Bennett, J. C. Tan, Y. Z. Yue, E. Baxter, C. D. Ducati, N. Terril, H. Y. Yeung, Z. Zhou, W. Chen, S. Henke, A. K. Cheetham and G. N. Greaves, Nat. Commun., 2015, 6, 10, DOI: 10.1038/NCOMMS9079.

6 K. W. Chapman, D. F. Sava, G. J. Halder, P. J. Chupas and T. M. Nenoff, J. Am. Chem. Soc., 2011, 133, 18583-18585.

7 F. X. Coudert, Chem. Mater., 2015, 27, 1905-1916.

8 D. Umeyama, S. Horike, M. Inukai, T. Itakura and S. Kitagawa, J. Am. Chem. Soc., 2015, 137, 864-870.

9 G. Givaja, P. Amo-Ochoa, C. J. Gomez-Garcia and F. Zamora, Chem. Soc. Rev., 2012, 41, 115-147.

10 J. Haines, C. Levelut, A. Isambert, P. Hebert, S. Kohara, D. A. Keen, T. Hammouda and D. Andrault, J. Am. Chem. Soc., 2009, 131, 12333-12338.

11 S. Jiang, K. E. Jelfs, D. Holden, T. Hasell, S. Y. Chong, M. Haranczyk, A. Trewin and A. I. Cooper, J. Am. Chem. Soc., 2013, 135, 17818-17830.

12 T. D. Bennett, A. L. Goodwin, M. T. Dove, D. A. Keen, M. G. Tucker, E. R. Barney, A. K. Soper, E. G. Bithell, J. C. Tan and A. K. Cheetham, Phys. Rev. Lett., 2010, 104, 115503.

13 S. L. James and T. Friscic, Chem. Soc. Rev., 2013, 42, 7494-7496.

14 A. D. Katsenis, A. Puskaric, V. Strukil, C. Mottillo, P. A. Julien, K. Uzarevic, M. H. Pham, T. O. Do, S. A. J. Kimber, P. Lazic, O. Magdysyuk, R. E. Dinnebier, I. Halasz and T. Friscic, Nat. Commun., 2015, 6, 10, DOI: 10.1038/ncomms7662.

15 T. D. Bennett, J. Sotelo, J. C. Tan and S. A. Moggach, CrystEngComm, 2015, 17, 286-289.

16 A. U. Ortiz, A. Boutin, A. H. Fuchs and F. X. Coudert, J. Phys. Chem. Lett., 2013, 4, 1861-1865.

17 J. C. Tan, B. Civalleri, C. C. Lin, L. Valenzano, R. Galvelis, P. F. Chen, T. D. Bennett, C. Mellot-Draznieks, C. M. ZicovichWilson and A. K. Cheetham, Phys. Rev. Lett., 2012, 108, 095502.
18 B. Van de Voorde, I. Stassen, B. Bueken, F. Vermoortele, D. De Vos, R. Ameloot, J. C. Tan and T. D. Bennett, J. Mater. Chem. A, 2015, 3, 1737-1742.

19 H. Wu, T. Yildirim and W. Zhou, J. Phys. Chem. Lett., 2013, 4, 925-930.

20 J. H. Cavka, S. Jakobsen, U. Olsbye, N. Guillou, C. Lamberti, S. Bordiga and K. P. Lillerud, J. Am. Chem. Soc., 2008, 130, 13850-13851.

21 L. Valenzano, B. Civalleri, S. Chavan, S. Bordiga, M. H. Nilsen, S. Jakobsen, K. P. Lillerud and C. Lamberti, Chem. Mater., 2011, 23, 1700-1718.

22 H. Wu, Y. S. Chua, V. Krungleviciute, M. Tyagi, P. Chen, T. Yildirim and W. Zhou, J. Am. Chem. Soc., 2013, 135, 10525-10532.

23 V. Guillerm, F. Ragon, M. Dan-Hardi, T. Devic, M. Vishnuvarthan, B. Campo, A. Vimont, G. Clet, Q. Yang, G. Maurin, G. Férey, A. Vittadini, S. Gross and C. Serre, Angew. Chem., Int. Ed., 2012, 51, 9267-9271.

24 Z. L. Fang, B. Bueken, D. E. De Vos and R. A. Fischer, Angew. Chem., Int. Ed., 2015, 54, 7234-7254.

25 G. C. Shearer, S. Chavan, J. Ethiraj, J. G. Vitillo, S. Svelle, U. Olsbye, C. Lamberti, S. Bordiga and K. P. Lillerud, Chem. Mater., 2014, 26, 4068-4071.

26 M. J. Cliffe, W. Wan, X. D. Zou, P. A. Chater, A. K. Kleppe, M. G. Tucker, H. Wilhelm, N. P. Funnell, F. X. Coudert and A. L. Goodwin, Nat. Commun., 2014, 5, 4176.

27 C. A. Trickett, K. J. Gagnon, S. Lee, F. Gandara, H. B. Bürgi and O. Yaghi, Angew. Chem., Int. Ed., 2015, 54, 1-7.

28 P. Ghosh, Y. J. Colon and R. Q. Snurr, Chem. Commun., 2014, 50, 11329-11331.

29 W. B. Liang, R. Babarao, T. L. Church and D. M. D'Alessandro, Chem. Commun., 2015, 51, 11286-11289.

30 W. B. Liang and D. M. D'alessandro, Chem. Commun., 2013, 49, 3706-3708.

31 G. Kresse and J. Furthmuller, Comput. Mater. Sci., 1996, 6, 15-50.

32 J. P. Perdew, K. Burke and M. Ernzerhof, Phys. Rev. Lett., 1996, 77, 3865-3868.

33 S. Grimme, J. Comput. Chem., 2006, 27, 1787-1799.

34 S. Grimme, J. Antony, S. Ehrlich and H. Krieg, J. Chem. Phys., 2010, 132, 154104.

35 J. Klimes, D. R. Bowler and A. Michaelides, Phys. Rev. B: Condens. Matter Mater. Phys., 2011, 83, 195131.

36 D. C. Langreth, B. I. Lundqvist, S. D. Chakarova-Kack, V. R. Cooper, M. Dion, P. Hyldgaard, A. Kelkkanen, J. Kleis, L. Z. Kong, S. Li, P. G. Moses, E. Murray, A. Puzder, H. Rydberg, E. Schroder and T. Thonhauser, J. Phys.: Condens. Matter, 2009, 21, 084203.

37 P. E. Blochl, Phys. Rev. B: Condens. Matter Mater. Phys., 1994, 50, 17953-17979.

38 G. Kresse and D. Joubert, Phys. Rev. B: Condens. Matter Mater. Phys., 1999, 59, 1758-1775.

39 H. J. Monkhorst and J. D. Pack, Phys. Rev. B: Condens. Matter Mater. Phys., 1976, 13, 5188-5192.

40 P. Giannozzi, S. Baroni, N. Bonini, M. Calandra, R. Car, C. Cavazzoni, D. Ceresoli, G. L. Chiarotti, M. Cococcioni, 
I. Dabo, A. Dal Corso, S. de Gironcoli, S. Fabris, G. Fratesi, R. Gebauer, U. Gerstmann, C. Gougoussis, A. Kokalj, M. Lazzeri, L. Martin-Samos, N. Marzari, F. Mauri, R. Mazzarello, S. Paolini, A. Pasquarello, L. Paulatto, C. Sbraccia, S. Scandolo, G. Sclauzero, A. P. Seitsonen, A. Smogunov, P. Umari and R. M. Wentzcovitch, J. Phys.: Condens. Matter, 2009, 21, 395502.

41 L. Kleinman and D. M. Bylander, Phys. Rev. Lett., 1982, 48, 1425-1428.

42 C. J. Pickard and F. Mauri, Phys. Rev. B: Condens. Matter Mater. Phys., 2001, 63, 245101.

43 G. Bruno and L. Randaccio, Acta Crystallogr., Sect. B: Struct. Crystallogr. Cryst. Chem., 1980, 36, 1711-1712.

44 F. Babonneau, L. Yeung, N. Steunou, C. Gervais, A. Ramila and M. Vallet-Regi, J. Sol-Gel Sci. Technol., 2004, 31, 219-223.

45 A. K. Soper, Tech. Rep. RAL-TR-2011-013, 2011.

46 S. Devautour-Vinot, G. Maurin, C. Serre, P. Horcajada, D. P. da Cunha, V. Guillerm, E. D. Costa, F. Taulelle and C. Martineau, Chem. Mater., 2012, 24, 2168-2177.

47 S. B. Kalidindi, S. Nayak, M. E. Briggs, S. Jansat, A. P. Katsoulidis, G. J. Miller, J. E. Warren, D. Antypov, F. Cora, B. Slater, M. R. Prestly, C. Marti-Gastaldo and M. J. Rosseinsky, Angew. Chem., Int. Ed., 2015, 54, 221-226.

48 P. He, B. E. G. Lucier, V. V. Terskikh, Q. Shi, J. X. Dong, Y. Y. Chu, A. M. Zheng, A. Sutrisno and Y. N. Huang, J. Phys. Chem. C, 2014, 118, 23728-23744.
49 G. Mali, J. Trebosc, C. Martineau and M. Mazaj, J. Phys. Chem. C, 2015, 119, 7831-7841.

50 P. He, J. Xu, V. V. Terskikh, A. Sutrisno, H. Y. Nie and Y. N. Huang, J. Phys. Chem. C, 2013, 117, 16953-16960.

51 H. C. Hoffmann, M. Debowski, P. Muller, S. Paasch, I. Senkovska, S. Kaskel and E. Brunner, Materials, 2012, 5, 2537-2572.

52 M. Baias, A. Lesage, S. Aguado, J. Canivet, V. Moizan-Basle, N. Audebrand, D. Farrusseng and L. Emsley, Angew. Chem., Int. Ed., 2015, 54, 5971-5976.

53 S. Oien, D. Wragg, H. Reinsch, S. Svelle, S. Bordiga, C. Lamberti and K. P. Lillerud, Cryst. Growth Des., 2014, 14, 5370-5372.

54 P. K. Allan, K. W. Chapman, P. J. Chupas, J. A. Hriljac, C. L. Renouf, T. C. A. Lucas and R. E. Morris, Chem. Sci., 2012, 3, 2559-2564.

55 J. E. Readman, P. M. Forster, K. W. Chapman, P. J. Chupas, J. B. Parise and J. A. Hriljac, Chem. Commun., 2009, 3383-3385. 56 D. A. Keen, J. Appl. Crystallogr., 2001, 34, 172-177.

57 C. L. Farrow, P. Juhas, J. W. Liu, D. Bryndin, E. S. Bozin, J. Bloch, T. Proffen and S. J. L. Billinge, J. Phys.: Condens. Matter, 2007, 19, 335219.

58 C. Kosanovic, J. Bronic, B. Subotic, I. Smit, M. Stubicar, A. Tonejc and T. Yamamoto, Zeolites, 1993, 13, 261-268.

59 T. Puclin and W. A. Kaczmarek, Colloids Surf., A, 1997, 129, 365-375. 